\title{
Article
}

\section{Refining and regaining skills in fixation/diversification stage performers: The Five-A Model}

Carson, H.J., and Collins, D.

Available at http://clok.uclan.ac.uk/12107/

Carson, H.J., ORCID: 0000-0002-3785-606X and Collins, D. ORCID: 0000-00027601-0454 (2011) Refining and regaining skills in fixation/diversification stage performers: The Five-A Model. International Review of Sport and Exercise Psychology, 4 (2). pp. 146-167. ISSN 1750-984X

It is advisable to refer to the publisher's version if you intend to cite from the work. http://dx.doi.org/10.1080/1750984X.2011.613682

For more information about UCLan's research in this area go to http://www.uclan.ac.uk/researchgroups/ and search for < name of research Group>.

For information about Research generally at UCLan please go to http://www.uclan.ac.uk/research/

All outputs in CLoK are protected by Intellectual Property Rights law, including Copyright law. Copyright, IPR and Moral Rights for the works on this site are retained by the individual authors and/or other copyright owners. Terms and conditions for use of this material are defined in the policies page.

\section{CLoK}

Central Lancashire online Knowledge www.clok.uclan.ac.uk

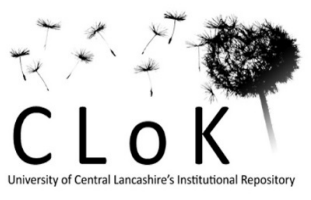


This is an Accepted Manuscript of an article published by Taylor \& Francis in International Review of Sport and Exercise Psychology on $1^{\text {st }}$ September 2011, available online:

http://dx.doi.org/10.1080/1750984X.2011.613682

\section{PLEASE REFER TO THE PUBLISHED VERSION FOR CITING PURPOSES}

Refining and Regaining Skills in Fixation/Diversification Stage Performers: The Five-A Model

Howie J. Carson* and Dave Collins

Institute for Coaching and Performance, University of Central Lancashire, UK

*Correspondence concerning this article should be addressed to Howie J. Carson, Institute for

Coaching and Performance, University of Central Lancashire, Preston, PR1 2HE. Email:

HJCarson@uclan.ac.uk 


\begin{abstract}
Technical change is one of many factors underpinning success in elite, fixation/diversification stage performers. Surprisingly, however, there is a dearth of research pertaining to this process or the most efficacious methods used to bring about such a change. In this paper we highlight the emergent processes, yet also the lack in mechanistic comprehension surrounding technical change, addressing issues within the motor control, sport psychology, coaching and choking literature. More importantly, we seek an understanding of how these changes can be made more secure to competitive pressure, and how this can be embedded within the process of technical change. Following this review, we propose The Five-A Model based on successful coaching techniques, psychosocial concomitants, the avoidance of choking and principles of effective behaviour change. Specific mechanisms for each stage are discussed, with a focus on the use of holistic rhythmbased cues as a possible way of internalising changes. Finally, we suggest the need for further research to examine these five stages, to aid a more comprehensive construction of the content and delivery of such a programme within the applied setting.
\end{abstract}

Keywords: Technical change, The Five-A Model, pressure resistance, elites 
Refining and Regaining Skills in Fixation/Diversification Stage Performers: The Five-A

\section{Model}

Despite possessing the demonstrable ability to perform at the highest level of proficiency and consistency, elite athletes still deploy a considerable number of hours to tweak or polish their techniques, even though the fundamental skills required for their given sport have long been learnt. Having reached the final (skill fixation/diversification) stage of learning (Gentile, 1972), athletes are expected to demonstrate long-term successful execution of a desired movement, not only consistently but also under differing contexts and levels of pressure. Crucially, however, they must also maintain or even enhance these characteristics while making changes to their technique. Accordingly, there is a need to identify and investigate effective methods for technical change at this 'postgraduate' end of the learning process. Such challenges are a constant feature of an elite performer's life (Smith, 2003) and clearly involve a significant 'mental' component. As such, supporting and optimising technical change can form a central part of the sport psychologist's contribution, while also representing an excellent ingression when building relationships with coach and athlete alike (Collins, 2008, 2009).

As identified earlier, technical change in elites will almost always take the form of adjustment to an already learnt, long practised and well established skill. As such, our paper is focused on changes to skills already well established at the fixation/diversification stage. The modification of technique in fixation/diversification stage athletes can be categorised in two distinct ways - the refinement and regaining of technique. Refinement reflects the evolution of technique in a way that is new to the athlete, for example when performing with changes to equipment design features (e.g., new javelins or 'clap' skates) as a way of searching for an optimal solution to the new problem. Another reason may result from the 
technical innovation of competitors, for example in ski jumping where the skis moved from a more closed to V-style position from one season to the next. Reflecting individual examples, the level of challenges sometimes faced by athletes can be represented by cases such as Bernhard Langer attempting several times to change his putting stroke (Trow, 1993) or Jessica Ennis switching her take off leg in the long jump (Minichiello, Rose, \& Brice, 2009). What is important to mention briefly at this stage is that applied interventions should reflect accurately the reason for change; that is, both the cause of error as well as the methods of solving it, something we will discuss later in more detail. Although these two examples are rather drastic, we should stress that technical refinement, albeit usually more subtle, is an almost constant aspect of training for elites, as every last second/metre/stroke/etc. advantage is sought. Regaining technique, by contrast, refers to returning from current suboptimum technique to an earlier stage when execution was more effective. This process can take place for any number of reasons, for example post injury (e.g., Golfer Luke Donald 'regaining' wrist mobility, strength and associated confidence when returning from injury; MizunoEurope, 2011). Regains may also be planned ('I was really good when. ..') independent of any trauma and reflect a desire to go 'back to basics' as a counter to overelaborate coaching, or to an earlier state associated with better outcomes.

Considering the clear importance of skill modification within sport, there is a surprising scarcity of studies that have sought to understand and/or explain the processes and methods leading to successful technical change within such an advanced movement system. This lies in stark contrast to learning skills, where noticeably greater efforts have been directed towards acquisition (e.g. Hall \& Magill, 1995; Horn, Williams, Hayes, Hodges, \& Scott, 2007; Williams \& Hodges, 2005). While this research has plenty of application within 
the development aspects of sport, it offers comparatively little to top ranked, outcome focused athletes competing under a plethora of social, global and personal pressures.

Reflecting these considerations, this paper proposes an integrated package of mental and other skills as a coaching 'tool'. The Five-A Model is designed to aid the optimisation of technical change in fixation/diversification stage performers in a way which facilitates change and maintains/enhances performance under pressure. As a basis to this approach, we review several areas of literature that provide the declarative knowledge of "what needs to be done', before offering the procedural knowledge of 'how to do it'.

\section{Mechanisms Underpinning Change - How it Might Work}

Research from several domains offers suggestions as to how technical change might work mechanistically. For instance, Bar-Eli (1991) highlighted the effective use of paradoxical interventions in counselling and sports coaching. In simple terms, a focus on emphasising what you do not want to occur highlights the distinctiveness of what you wish for. Bar-Eli (1991) relates these ideas to those of 'reframing' (Watzlawick, Weakland, \& Fisch, 1974) within the context of sport consultation, on the premise that the natural human response will be 'to search for a new action strategy in order to satisfy the same governing variables' when presented with such a 'mismatch' (Bar-Eli, 1991, p. 62). Argued by action scientists as occurring mainly through a self-reflection of one's actions (Markova, 1987; Schoen, 1983), this approach indicates the requirement for a 'calling into consciousness' or making explicit some form of tacit knowledge contained within the action itself (see also Argyris, Putnam, \& Smith, 1985 on double-loop learning processes).

More recently, Mercado $(2008,2009)$ has offered insightful suggestions into the neurological changes within the brain during the process of change. In summary, the 
reorganisation of neural networks or cortical modules increases the capacity to resolve stimulus representations: a reference to neural activity caused by sensory receptors, movement and/or thoughts, indicating a perturbation by an internal or external state. Thus, the ability to resolve these representations will determine what is learnt. Key to this resolving ability (termed representational resolution), is to distinguish between the stimuli which, in turn, results in a learnt response associated with the two representations and a change in the neural networking (i.e., hard wiring).

Lastly, experimental work from Kostrubiec, Zanone, and colleagues (e.g., Kostrubiec, Tallet, \& Zanone, 2006; Kostrubiec \& Zanone, 2002; Tallet, Kostrubiec, \& Zanone, 2008, 2010) has associated the level of competition between the current and desired movement pattern to affect its overall endurance over time. One possible route of reducing competition is by bifurcation, a sudden creation of a new stable pattern; the other is by shift, a gradual change towards a to-be-learnt pattern. However, where the shift method leads to greater initial accuracy, it suffers from lower stability compared to the bifurcation method, which leads to a more specific and stable change in the memory repertoire. Consequently, during recall trials (after removing a stimulus model) the shift learnt pattern returns to a stable but not necessarily pre-existing movement pattern, while the bifurcation learnt pattern would endure as a new and stable movement. This short-term shift effect can be illustrated by a regression back towards a natural (individually preferred) rhythm of cycling on removal of a metronome induced rhythm (MacPherson, Turner, \& Collins, 2007).

In short, reflecting these bodies of research, technical change could be viewed as a process of generating then distinguishing between alternatives, signifying a parallel process of becoming 'unfixated' or more 'specialised', followed by establishing ability for movement fixation/diversification. This indicates, therefore, that at least in the early stages, an athlete 
must undergo a perturbation as an essential precursor to generating new alternatives; or to put this concept into an analogy, unlocking the black box (i.e., mind) and removing the component parts. The gap within this literature appears in the ways in which the new skill may best be firmed up, distinguished and pressure-proofed: or to continue the analogy, how the black box can be shut and locked, remaining so under immense competitive pressure.

A special case must also be made for the regaining as opposed to the refinement of skills. We have hopefully now established that the process of technical change should be explained as a distinct process from initial learning. This means that, mechanistically, the processes for regaining and refining skills must also be subtly different, therefore suggesting diverse methods for achieving each result. This should not only have implications on the time scales involved compared to refining skills, but also towards the decision-making process between athlete and coach, i.e., when faced with the need to alter technique, what is the best strategy, refine or regain? There is thus a need to establish proven training programmes for such circumstances when they arise in elite sports coaching.

Finally, explicit recognition must be given to the process through which the need for and direction of change is decided. Research increasingly shows a great deal of interindividual variability in the movement patterns of elite performers (Chow, Davids, Button, \& Koh, 2006). As such, advice to a high-level performer to 'do it this way because Tiger does' is almost inevitably doomed to failure. Although it may be that, for some skills and some learners, an optimal solution can be discerned (cf. Peh, Chow, \& Davids, 2011), it is far more usual that the direction of the change needs to be carefully evaluated against these individual characteristics. For example, as stressed by Newell, Liu, and Mayer-Kress (2005, p. 46), 'different types of information are differentially effective depending on the task to be learned 
and the skill level (dynamic state) of the learner'. As such, detailed and individually focused analyses must be an essential precursor to any decision to change.

\section{Theoretical Issues and Caveats}

In view of the suggested mechanisms above, we feel it appropriate at this stage to discuss any theoretical contradictions within the literature and attempt to resolve possible concerns that may arise. Most strikingly, readers may question the requirement to call into consciousness or make explicit some form of movement component. In contrast to commoncoding theory (Prinz, 1990) and the constrained-action hypothesis (Wulf, 2007), this evidently goes against the reported benefits associated with an external focus of attention. However, a recent review of the attentional focus literature by Peh et al. (2011) has highlighted specific concerns over research in this area. Firstly, the authors emphasise the intended goals of these studies to determine the relative efficacy of either an internal or external focus in isolation. This arguably distances the findings from the dynamic process of learning over multiple time scales (including transitory phases) (Newell, Liu, \& Mayer-Kress, 2001). As such, advocating an external focus of attention may fail to exploit any advantages of focusing internally during earlier stages of learning (e.g., Beilock, Bertenthal, McCoy, \& Carr, 2004). Methodologically, the authors raised concerns over the extent to which an attentional focus is monitored during experimental tasks (see also Maxwell \& Masters, 2002); arguing the adoption of multiple attentional foci as a metastrategy could be most beneficial. The same argument may be true for implicit learning (Masters, 1992), whereby research in this area has been seen to shift away from impractically coached methodologies, e.g., removing outcome feedback and errorless learning (Masters, Maxwell, \& Eves, 2009), towards more practical solutions such as analogy learning (Lam, Maxwell, \& Masters, 2009). This suggests somewhat of an evolving argument that some conscious processing is permitted 
providing it does not 'overwhelm' attentional resources. From an applied sense, using a metastrategy supports the Five-Step Strategy (Singer, 1988, 2000), which describes pre-, actual and post-performance states for closed skill aiming tasks. Briefly, the five steps are:

(1) readying by establishing a routine that involves optimal positioning of the body, confidence, expectations, and emotions; (2) imaging a picture and the feeling of performing an act at one's best; (3) focusing attention on a relevant external cue or thought; (4) executing with a quiet mind; and (5) evaluating (if time permits) the quality of execution of the act and the outcome as well as the implementation of the previous four strategies" (Singer, 2000, p. 1669).

As is evident from this established routine and numerous supportive empirical studies (e.g., Kim, Singer, \& Radlo, 1996; Singer, DeFrancesco, \& Randall, 1989; Singer, Lidor, \& Cauraugh, 1993; Steinberg \& Glass, 2001), an internal focus can play an important role in the execution and learning of a motor skill, especially when there is a greater dependency on the movement's form (Peh et al., 2011). What is missing from the Five-Step Strategy is an application towards performers who already have well established, fixated/diversified control over actions. Instead, this approach has only been tested and advocated for the learning and performance of closed skills.

Lastly, while skill acquisition theories (e.g., Bernstein, 1967; Fitts \& Posner, 1967; Gentile, 1972) promote unidirectional learning stages, it is empirically somewhat unclear how the possible dynamic nature of attentional foci use could impact on a performer's characteristics at the very expert end of this continuum whilst attempting to implement a change. Arguably, studies investigating mental processes as well as movement kinematics during times of change may provide possible answers to this problem. This is clearly an important and very complex issue for skill acquisition experts to address and one that is 
somewhat unclear at best. However, it is not one that we see fit to fully address in the applied context of this paper, hence our approach to explore this issue using different specific theories from closely related domains.

Clearly work has begun in this area, however if it is to have any such application to sport, psychologists and coaches must also start reporting not only successful but also unsuccessful cases of technical change, which will help inform theory and vice versa.

\section{Achieving Technical Change - What Methods have been tried?}

Reflecting the ideas and concepts explored above, the next section considers some representative exemplars of technical change in discrete sport skills which have been reported in the literature.

\section{Regaining Technique in Javelin Throwing}

Collins, Morriss, and Trower (1999) report a successful case study of regaining technique post injury with an Olympic javelin thrower. The desired aim was to bring about a sudden reversal of technique to a previously optimal version, the cause being attributed to either unconscious inhibition or trace decay. Their intervention also targeted an increase in comfort and confidence associated with the old technique. 'Contrast' drills were used initially to increase awareness of the correct versus incorrect positioning, and to internalise the key movement characteristics. Two versions of drills were used with three step run-ups. The first drill forced greater concentration and kinaesthetic consequences of the movements achieved through both left and right handed throwing. The other demanded deliberate throwing with correct (old) and incorrect (current) positioning, which were then cued and used to signify the different techniques. During this phase, the numbers of left handed or incorrect throws were tapered out, challenging the athlete to produce longer spells of the correct technique. Phase two reintroduced the full length stride prior to the throw, again using left handed or incorrect positioning. To aid the athlete's transfer of technique into the 
full stride, an audiotape was prepared, consisting of short bleeps representing correct footground contact timings. Pitch was manipulated, corresponding to perceived intensity and/or specific phases of the run-up and throw, which was then used to support imagery practice. A third phase incorporated the previous drills into a strenuous training session. The three step drills were distributed throughout a series of sprints, and full length run-ups with a 150-m stride between trials. Lastly, throws preceded by $50-\mathrm{m}$ sprints were carried out under full competitive simulations. Although coach feedback was given throughout the previous phases, in this last phase a full kinematic analysis was completed to show how the technique had improved. The reported modification, i.e., technical regain, was still apparent at least two years following the intervention, resulting in a return to previous throwing distances achieved four years prior.

\section{Refining Technique in Swimming}

In a subsequent but somewhat similar example, Hanin, Malvela, and Hanina (2004) improved the diving technique of an Olympic swimmer using an 'old way/new way' method. Whereas Collins et al. (1999) worked to regain technique, this scenario sought to refine an over-learnt technical error with the aim of a rapid correction time. To achieve this, an initial distinction between the incorrect and desired dive was established among the athlete, coach and researcher. An error correction procedure then followed, consisting of four steps. The first required the swimmer to develop a physical and mental awareness of the incorrect technique. Step two worked to develop an awareness of the new correct technique through bodily sensations. This is explained to be a quick transition because the cause of error early on was fully understood. Similarly to Collins et al. (1999), step three discriminated between the old and new technique, explicitly referring to each trial as an old or new way. Lastly, variable practice was introduced by altering glance direction, gliding distances, the first kick and pull. These conditions were also carried out under accumulated fatigue during the 90- 
minute session. The results reported $85 \%$ of correct starts in the National Championships after three days, and $94 \%$ of correct starts eight months following the intervention, though based only on faster starting times.

\section{Refining Technique in Weightlifting}

A third example of technique refinement is reported by Carson, Collins, and Jones (submitted). In this case study involving an Olympic weightlifter, the reason for change was injury driven, brought about by a long-term technical fault whilst performing the two hand snatch. The intervention was divided into five stages, starting with the athlete recreating the position that had caused an injury, but replacing the bar with a broomstick. This position was then manipulated towards a new, more effective and less injury prone technique, enabling the athlete to generate an awareness and cues for the different feelings and positions. By stage two, the athlete could lift a $20 \mathrm{~kg}$ bar, which was used to perform correct lifts followed by incorrect lifts, emphasising the kinaesthetic sensations between the two lifts. Again, similar to Collins et al. (1999), incorrect trials were gradually faded out. Discrimination between lifts, evaluation and further cueing to heighten kinaesthetic awareness, acceptance and comfort were central to this stage as well as the introduction of imagery. Concurrently, the athlete consulted with experts to better understand his injury, helping to develop an action plan and build his confidence. Stage three saw the earlier developed cues refined and introduced into an imagery script, practised regularly both visually and kinaesthetically. As the technique became refined and the sensations changed, these were introduced into the imagery script, as a form of 'shaping'. This was aided by the use of video feedback showing best attempts; thus providing evidence of an ever improving self-coping model. Stage four was characterised by increasing the weight of the bar and reforming the imagery script accordingly. It was important that the planned targets were met. Lastly, once maximal weight could be achieved, competitive simulations were carried out and introduced within the 
imagery script for pre-event preparation. Video and kinematic feedback were important elements of this final stage. The kinematic results show significant improvements in technique during the six week intervention and further improvements both after 55 weeks and two years.

\section{Comparison and contrast - Contextualising exemplars against the literature}

Despite movement differences, all of these studies share common principles related to the proposed theories of change mentioned earlier. For example, each intervention emphasised two contrasting techniques, e.g., 'old way/new way' (Hanin et al., 2004), correct versus incorrect (Collins et al., 1999) and position manipulation (Carson et al., submitted), to gain an awareness of change, showing support for the suggestions of Bar-Eli (1991), Mercado $(2008,2009)$ and Kostrubiec and colleagues. This act of comparing and contrasting should be viewed as a coaching tool designed to call into consciousness, or differentiate between possibilities. In other words, in order to initiate the change process, a 'wedge' must be driven between the current and desired movement pattern to generate a distinction and realise the required changes.

Contrary to this idea of contrast, however, is the effectiveness of shifting or 'shaping technique' as the authors referred to it. These case studies illustrate that, once the distinction has been made, i.e., the wedge has been driven, gradual change is possible, for example through fading out techniques (e.g., increasing the frequency of demonstrating the new technique) or modified imagery scripts based on best performances, as a means of 'modifying the contents of the black box'. So, from a process point of view, the shaping technique may not be an effective method of change in isolation, but can clearly be used to good effect during an adjustment stage. These findings can be compared to the suggestions of Schöllhorn, Mayer-Kress, Newell, and Michelbrink (2009), stating that a sufficient level of 
'noise' is required to enable mobility away from a stable attractor, gradually reducing the noise levels once the performer has come close to the targeted performance outcome.

Additionally, the use of holistic rhythm-based cues has been reported to generate an effective focus without fragmenting the to-be-learnt movement (MacPherson, Collins, \& Obhi, 2009), suitable for regaining consistency and an optimal mental state as demonstrated prior to change (executing with the new technique of course!). An example of such usage can be highlighted from the exemplars above as the tone-based run-up and execution (Collins et al., 1999). This is something we will discuss in greater detail later. Lastly, attempts to make changes secure were explicitly included, through either pressure testing and/or variable practice, which serves to enhance the transferability of the learnt movement pattern and provides a useful indicator of readiness to compete once again, both in closed and open environments.

In either case of refinement or regaining of skill, there are a number of well reported additional 'psychosocial' factors which appear to be highly influential in determining the success of any prescribed intervention. Typical factors can be exemplified as involvement within the process, commitment/monitoring progress (goals), trust and confidence. This reflects an overall suggestion that 'buying into the change' should be included as an explicit feature of the change process, during both an educational phase as well as an ongoing outcome for the psychologist and coach whilst implementing an intervention. Each of these factors will be addressed in greater detail in the next section. We also recommend that interested readers should review the papers referenced above, as these psychosocial factors were not wholly the focus of the current section yet were still applied in all cases.

\section{Supporting Technical Change - Psychosocial Concomitants}

\section{Involvement in the process}


Technical change for any fixation/diversification stage athlete should involve a detailed and in-depth decision-making process. Applied research utilising performance profiles has been shown to be very effective when working with an elite athlete (Jones, 1993) or team (Dale \& Wrisberg, 1996). The mechanisms underpinning performance profiling provide a good explanation for why an athlete's involvement is important. This approach draws together both the idea that an athlete's understanding of the world is central to the learning experience, as emphasised by Kelly’s (1955) Personal Construct Theory, and also the standpoint that athletes are often too passive to the coaching experience (Tyler, 1949). By incorporating perspectives from both coach and athlete, a balanced view towards the designing of training programmes is created (Butler, 1999). This underpinning incorporates both the athletes' needs relative to the demands of the sport together with the knowledge of the coach, representing a transformational leadership style (Martens, 1987), whereby both agencies work together to diagnose and plan an appropriate intervention targeting the cause of the problem; deciding that the black box needs to be opened. In doing so, it helps maximise athlete motivation, empowerment and adherence towards programmes, attributed to perceived respect and value exchanged by the coach and athlete (Butler \& Hardy, 1992). Crucially, however, athlete involvement can help ensure that the idea is bought into, with shared responsibility/accountability between coach and athlete throughout.

\section{Commitment/monitoring progress (goals)}

Sport commitment can be defined as the sum of one's resolve and the desire to continue participation in one's sport. It thus reflects the motivational driving force behind one's involvement as well as an important underpinning of persistence (Scanlan, Carpenter, Schmidt, Simons, \& Keeler, 1993). An expanded version of the original Sport Commitment Model (Scanlan et al., 1993) proposes that psychological commitment can be predicted by enjoyment, involvement opportunities, investments, attractive alternatives and perceived 
costs, with investments and perceived costs predicting behavioural commitment (Weiss, Weiss, \& Amorose, 2010). One method of engaging an athlete within the change process and becoming committed is to use goal setting and monitoring procedures (see Locke \& Latham, 2002 for a review of goal setting mechanisms). In monitoring the impact of conventional sport psychology interventions, Anderson, Miles, Mahoney, and Robinson (2002) propose the use of multiple evaluative measures (objective and subjective) to ensure triangulation, incorporating both performance and psychological skills. Overall, in the present context, commitment should be viewed as a central construct for buying into the change, with goal setting and monitoring as a means of maintaining optimal levels of commitment during the programme implementation.

\section{Trust}

Trust is a psychological skill defined as 'letting go of conscious controlling tendencies and allowing automatic processes, which have been developed through training, to execute a motor skill' (Moore \& Stevenson, 1991, p. 282). As such, it is facilitating the mechanisms of automaticity and enabling a focus towards the more comprehensive features of action planning, without expectation (or fear) relating to movement or outcome (Moore \& Stevenson, 1991). Increasing trust thus decreases the need for conscious control. These feelings are confirmed by reports from elite athletes (Jackson, 1996), and support general models of flow states (Csikszentmihalyi, 1990). Trust can be characterised by specificity (skill and situational), magnitude (categorical; i.e., yes or no) and stability (endurance over situation and time) (Moore \& Stevenson, 1991). Therefore, like an athlete modifying their technique, it is never mastered. Moore and Stevenson (1994) propose that training trust is a way of better preparing athletes to express automaticity during behaviour change, which seems appropriate when addressing refinement and regains of technique. This has been achieved through education, skills training and competitive simulations with positive effects 
on outcome and temporal movement characteristics (Stevenson et al., 2007). Accordingly, specific design features to instil trust from start to finish, beyond the change itself, appear vital in how the process of change is to be operationalised. So, in relation to our earlier analogy, trust plays an important role in the opening of the black box, but also in the locking and securing of the lid during times of pressure.

\section{Confidence}

The consequences of possessing appropriate confidence levels can be represented by an $\mathrm{ABC}$ triangle (Vealey, 2001), referring to an athletes' affect (A), behaviour (B) and cognitions (C). Accordingly, optimal confidence stimulates positive emotions, is linked to productive achievement behaviours, e.g., effort and persistence, and produces more skilled and effective use of cognitive resources, e.g., attribution patterns, attentional skills and coping strategies, which is correlated to higher levels of performance (George, 1994). Confidence within the process of technical change is of clear importance during the buying in period. In this sense, the sport psychologist and coach must convince the athlete to have confidence in the change programme and their ability to implement it successfully, reflecting the importance of and need for a harmonious coach-athlete relationship (Lafrenière, Jowett, Vallerand, \& Carbonneau, 2011). Likewise, as a component of keeping the box locked under pressure, the athlete must have regained confidence not only in the execution of the skill, but also in knowing it will be secure under pressure, thus increasing the resistance towards conscious control. This task of building self-confidence appears to be complemented by the sources and types of confidence elicited by world class athletes, e.g., preparation, coaching, skill execution (Hays, Maynard, Thomas, \& Bawden, 2007), and should therefore remain essential to achieving Vealey's (2001) ABCs. 
In attempting to bring about technical changes that are secure against pressure, it may be useful at this point to briefly examine the scenario of failure under pressure and why that might happen; if only to inform us of what to avoid.

\section{Failures in Technical Change - Where, When and Why they may Occur}

Failure to execute a movement correctly in sport is an unfortunate reality of many competitive encounters. When undergoing a technical change, it is sometimes not until this 'moment of truth' that an athlete sadly realises their hard work was simply not enough. Failure to securely fixate/diversify a recent modification can often be the underlying reason behind a collapse in technical performance - for example, Tiger Woods struggling with his return to competitive golf during the 2011 season whilst undergoing a technical 'rebuild' (Ross, 2011).

The phenomenon of collapse is frequently referred to in the literature as 'choking under pressure'. This can be defined as: "heightened levels of perceived pressure and where incentives for optimal performance are at a maximum lead to acute or chronic forms of suboptimal performance or performing more poorly than expected given one's skill level and self-set performance expectations" (Gucciardi, Longbottom, Jackson, \& Dimmock, 2010, p. 79). Choking can therefore be viewed as a psycho-physiological construct, whereby the interplay between mental and physical responses leads to an inevitable process of decline.

Mechanistically, the choking event can be underpinned by an induced (but inappropriate) self-focus during the time of movement execution. This is often reported by athletes in a way such as 'thinking too much about the processes and losing the automaticity that is there when I'm shooting at my best' (Gucciardi et al., 2010, p. 70). Two prominent self-focus theories to date are the Explicit Monitoring Hypothesis (EMH; Beilock \& Carr, 2001) and the Conscious Processing Hypothesis (CPH; Masters, 1992). EMH states that performance decrements occur because the athlete consciously monitors their actions, 
whereas $\mathrm{CPH}$ states that it is the conscious controlling of movements. Choking in either case is thus caused by an overloading of the working memory, preventing the more subtle environmental/task-related cues from being processed, in an attempt to exert greater effort. Reflecting on the findings of Beilock et al. (2004), novice performers were aided by conscious awareness whereas experts were not, due probably to the breakdown in automaticity. Self-focus theories therefore represent a cognitive regression in the stages of learning (Fitts \& Posner, 1967; Gentile, 1972) brought about by increased anxiety. In either case of EMH or $\mathrm{CPH}$, we can use our analogy to emphasise that not locking and securing the black box following a period of technical change leads to the opportunity for one to reopen it and demonstrate excessive cognition during times of pressure. Hence the purpose of our research is targeted at promoting technical change that is resistant to such processes under pressure.

Further support for the notion that performance regresses to an earlier stage of learning is demonstrated by kinematic and physiological-based experiments. Higuchi, Imanaka, and Hatayama (2002) reported delayed movement initiation times, reduced movement amplitude and low inter-trial variability of spatial kinematics for a computer batting task when subjected to psychological stress. Pijpers, Oudejans, Holsheimer, and Bakker (2003) found evidence of higher heart rates, increased muscle fatigue (through tension) and blood lactate concentrations when wall climbing at two different heights. This manifested into longer trial durations and higher entropy of climbing trajectory, i.e., less smooth displacement of the climbers' centre of gravity. All of these are signs of biological or kinematic inefficiencies associated with earlier stage learners. Very similar results were shown for both simple stepping and more complex but well learnt weight lifting skills (Collins, Jones, Fairweather, Doolan, \& Priestley, 2001). These findings support a notion 
that anxiety reverses the necessary fixation/diversification of movement control (Gentile, 1972).

One possible reason why an athlete's technique might not stand up under pressure is the inappropriate use of information 'cues' (MacPherson, Collins, \& Morriss, 2008), sometimes referred to as 'keys' (Jenkins, 2007) employed by conventional coaching practice. MacPherson et al. (2009) explain how using movement-related cues can serve to fragment and disrupt the flow of movement under pressure. We have established that well learnt movements are processed offline or subconsciously, supported perhaps by evolving cortical networks in different regions of the brain (Mercado, 2009). When performing at this stage of learning or level of control, movements have a self-organising tendency to perform at optimal efficiency (refer to MacPherson et al., 2007), rhythm being an important feature of organising the many control subsystems. From an applied point of view, therefore, rhythm should be seen as an underlying cause of optimum performance, providing a 'source of information' that stresses the overall control of the task but which does not overload the working memory (MacPherson et al., 2008). Accordingly, we should emphasise how inappropriate emotions, cognitions and anxiety interpretations serve to inhibit the sequencing, timing and impact of rhythm on the control efficiency during highly fixated/diversified movements. Indeed, as shown above, disruption to rhythmicity during the execution of movements can cause a regression in control functions and performance outcome (Collins et al., 2001; Higuchi et al., 2002; Pijpers et al., 2003). These cues or keys (ironically using our analogy) thus actively open up the black box during scenarios of competitive pressure and draw attention away from the action's entirety.

Extreme cases of skill failure have been reported in the form of lost move syndrome (LMS), whereby an athlete regresses so much so that they are unable to perform what appear to be the simplest of tasks. Very little literature has been written on this syndrome; however, 
Day, Thatcher, Greenlees, and Woods (2006) report insights from a trampoline context. As explained by the self-focus theories described earlier, higher anxiety (fear of the move) directed attention inward as added meaning and importance to succeed became more of an issue. This anxiety was heightened due to perceived social pressures from coaches and relatives. Noticeably, the condition of LMS was reported to have possibly been influenced in part by the process of skill acquisition. In cases where skills had been learnt either in a short and rushed or difficult and slow manner, LMS had emerged. It could therefore be argued that if skills are not sufficiently delineated from one another during the learning process, regression in a similar way to the shifting technique used by MacPherson et al. (2007) will emerge under pressure. In other words, where experts would normally consciously process declarative knowledge during the choking experience, this was absent due to an initially incomplete knowledge structure. The occurrence of LMS highlights the further need to understand the learning environment, appropriate incorporation of psychosocial factors and methods used to secure skills that are clearly fixated/diversified.

\section{Synthesising the Literature - The Five-A Model}

Having reviewed the literature above, we hope to have emphasised the current need for addressing such an issue of technical change in fixation/diversification stage performers, and established an expected framework for The Five-A Model. Bringing our analogy together, The Five-A Model can be used to describe a process of (a) deciding which part of the black box to open (Analysis), (b) unlocking the black box and removing the component parts (Awareness), (c) modifying the contents of the box (Adjustment), (d) replacement in and locking of the box (Re-Automation) (e) hiding the key where neither coach nor athlete can find it (Assurance), see Table 1.

\section{Future Research}


In proposing the Five-A Model we seek to provide a coaching tool aimed at aiding the optimisation of technical change in fixation/diversification stage performers. Consequently, we offer several directions for future research in this area. Firstly from a mechanistic standpoint, we would welcome researchers from different perspectives to begin investigating in greater detail the mechanisms for change. We can suggest, but by no means insist, using our analogy or any of the ideas presented in this paper as a reasonable starting point. Indeed, our own future research will aim to include some elements of such testing as well as a measure of the unique contribution offered by the model to current practice. This is clearly a complex and time enduring issue, one that we hope will be extended by researchers within the motor control and skill development domains.

Secondly, as mentioned at the start of this paper, when designing interventions for change, it is crucial that the prescription treats the actual cause of the problem. Expanding on one of our earlier examples, Bernhard Langer's problem with the 'yips' could be diagnosed as choking under pressure, in which case a psychological intervention would seem appropriate. However, it could equally be due to a focal, task specific dystonia and not caused by anxiety or an internal focus under pressure at all (Smith et al., 2003). As such, defining the cause of the problem and relating it to an appropriate intervention is a very important consideration during the Analysis stage of the Five-A Model. Consequently, more studies which report analytical procedures (rationale and format) within the applied setting would be an ideal addition in supporting accurate diagnoses as a precursor to change, including 3D modelling as well as possible psychological and performance-based evaluations.

Thirdly, there is a clear deficiency in the literature surrounding interventions which may be used to pressure-proof changes. While research shows positive relationships between performance and confidence (Woodman \& Hardy, 2003) as well as identifying various 
sources of confidence (Hays et al., 2007, 2009), greater research is required from a practitioner's perspective as to how these sources of confidence can be utilised to maximise performance under pressure.

Lastly, from an applied perspective, research should seek to explore the extent to which the Five-A Model is exploited in practice, both in terms of structure (i.e., stages, if any) and procedures (tools). In doing so, it should add authentication to our claim that what we are saying is nothing new; rather, we are simply bringing together research previously viewed in isolation in order to solve a complex and multifaceted problem. Sport psychologists and scientists will also be better able to evaluate the current strengths and weaknesses within applied coaching practice at a domain specific level, whilst also developing a larger 'toolkit' for implementing each stage.

\section{Conclusion}

In summary, we have suggested the necessity and, hopefully, laid the foundations for a five stage model of technical change targeted at fixation/diversification stage athletes. This model is aimed at being employed by coaches, though closely guided by the sport psychologist. Informed by several studies, central components of this model include differentiation, shaping, holistic cues and confidence in locking the black box. We further suggest those involved with the process be not only multi- but also inter-disciplinary, as a means of triangulation and aiding the athlete to buy into the process. On reflection, the most compelling focus of research is for the examination and optimisation of the Five-A Model. 


\section{References}

Anderson, A. G., Miles, A., Mahoney, C., \& Robinson, P. (2002). Evaluating the effectiveness of applied sport psychology practice: Making the case for a case study approach. The Sport Psychologist, 16(4), 432-453.

Argyris, C., Putnam, R., \& Smith, D. M. (1985). Action Science. San Francisco: Jossey-Bass. Armstrong, S. (2001). Are you a "transformational" coach? Journal of Physical Education, Recreation and Dance, 72(3), 44-47.

Bar-Eli, M. (1991). On the use of paradoxical interventions in counseling and coaching in sport. Sport Psychologist, 5(1), 61-72.

Bass, B. M. (1999). Two decades of research and development in transformational leadership. European Journal of Work \& Organizational Psychology, 8(1), 9-32. doi: $10.1080 / 135943299398410$

Beilock, S. L., Bertenthal, B. I., McCoy, A. M., \& Carr, T. H. (2004). Haste does not always make waste: Expertise, direction of attention, and speed versus accuracy in performing sensorimotor skills. Psychonomic Bulletin \& Review, 11(2), 373-379.

Beilock, S. L., \& Carr, T. H. (2001). On the fragility of skilled performance: What governs choking under pressure? Journal of Experimental Psychology: General, 130(4), 701725.

Bernstein, N. A. (1967). The Coordination and Regulation of Movements. Oxford: Pergamon Press.

Butler, R. (1999). Performance Profiling (2nd ed.). Leeds: The National Coaching Foundation.

Butler, R. J., \& Hardy, L. (1992). The performance profile: Theory and application. Sport Psychologist, 6(3), 253-264. 
Carson, H.J., Collins, D., \& Jones, B. (submitted). A case study of technical change and rehabilitation: Intervention design and multidisciplinary team interaction.

Chow, J. Y., Davids, K., Button, C., \& Koh, M. (2006). Organization of motor system degrees of freedom during the soccer chip: An analysis of skilled performance. International Journal of Sport Psychology, 37(2/3), 207-229

Collins, D. (2008). Where from here? Reflections on Being. Paper presented at the British Association of Sport and Exercise Sciences Annual Conference, Brunel University, September.

Collins, D. (2009). Strange Bedfellows: WHY sport AND exercise psychology? . Paper presented at the Inaugural British Psychological Society DSEP Conference, London, December.

Collins, D., Jones, B., Fairweather, M., Doolan, S., \& Priestley, N. (2001). Examining anxiety associated changes in movement patterns. International Journal of Sport Psychology, 32(3), 223-242.

Collins, D., Morriss, C., \& Trower, J. (1999). Getting it back: A case study of skill recovery in an elite athlete. Sport Psychologist, 13(3), 288-298.

Csikszentmihalyi, M. (1990). Flow: The Psychology of Optimal Experience. New York: Harper \& Row.

Dale, G. A., \& Wrisberg, C. A. (1996). The use of a performance profiling technique in a team setting: Getting the athletes and coach on the "same page". Sport Psychologist, 10(3), 261-277.

Davids, K., Button, C., Araújo, D., Renshaw, I., \& Hristovski, R. (2006). Movement models from sports provide representative task constraints for studying adaptive behavior in human movement systems. Adaptive Behavior, 14(1), 73-95. doi:

$10.1177 / 105971230601400103$ 
Day, M. C., Thatcher, J., Greenlees, I., \& Woods, B. (2006). The causes of and psychological responses to lost move syndrome in national level trampolinists. Journal of Applied Sport Psychology, 18(2), 151-166.

Desjardins, G., Jr. (1996). The mission. In J. H. Salmela (Ed.), Great Job Coach! Getting the Edge from Proven Winners (pp. 69-100). Ottawa, ON: Potentium.

Fitts, P. M., \& Posner, M. I. (1967). Human Performance. California: Brooks/Cole Publishing Company.

Frank, T., Michelbrink, M., Beckmann, H., \& Schöllhorn, W. (2008). A quantitative dynamical systems approach to differential learning: self-organization principle and order parameter equations. Biological Cybernetics, 98(1), 19-31. doi: $10.1007 / \mathrm{s} 00422-007-0193-\mathrm{x}$

Gentile, A. M. (1972). A working model of skill acquisition with application to teaching. Quest, 17(1), 3-23.

George, T. R. (1994). Self-confidence and baseball performance: A causal examination of self-efficacy theory. Journal of Sport \& Exercise Psychology, 16(4), 381-399.

Gucciardi, D. F., Longbottom, J.-L., Jackson, B., \& Dimmock, J. A. (2010). Experienced golfers' perspectives on choking under pressure. Journal of Sport \& Exercise Psychology, 32(1), 61-83.

Hall, K. G., \& Magill, R. A. (1995). Variability of practice and contextual interference in motor skill learning. Journal of Motor Behavior, 27(4), 299-309.

Hanin, Y., Malvela, M., \& Hanina, M. (2004). Rapid correction of start technique in an olympic-level swimmer: A case study using old way/new way. Journal of Swimming Research, 16(1), 11-17. 
Hays, K., Maynard, I., Thomas, O., \& Bawden, M. (2007). Sources and types of confidence identified by world class sport performers. Journal of Applied Sport Psychology, 19(4), 434-456.

Hays, K., Thomas, O., Maynard, I., \& Bawden, M. (2009). The role of confidence in worldclass sport performance. Journal of Sports Sciences, 27(11), 1185 - 1199.

Higuchi, T., Imanaka, K., \& Hatayama, T. (2002). Freezing degrees of freedom under stress: Kinematic evidence of constrained movement strategies. Human Movement Science, 21(5-6), 831-846.

Hill, D. M., Hanton, S., Matthews, N., \& Fleming, S. (2010). Choking in sport: a review. International Review of Sport and Exercise Psychology, 3(1), 24-39.

Horn, R. R., Williams, A. M., Hayes, S. J., Hodges, N. J., \& Scott, M. A. (2007). Demonstration as a rate enhancer to changes in coordination during early skill acquisition. Journal of Sports Sciences, 25(5), 599-614.

Jackson, S. A. (1996). Toward a conceptual understanding of the flow experience in elite athletes. Research Quarterly for Exercise and Sport, 67(1), 76-90.

Jenkins, S. (2007). The use of swing keys by elite tournament professional golfers. International Journal of Sports Science and Coaching, 2(1), 199-229.

Jones, G. (1993). The role of performance profiling in cognitive behavioral interventions in sport. Sport Psychologist, 7(2), 160-172.

Kelly, G. A. (1955). The Psychology of Personal Constructs. New York: Norton.

Kim, J., Singer, R. N., \& Radlo, S. J. (1996). Degree of cognitive demands in psychomotor tasks and the effects of the Five-Step Strategy on achievement. Human Performance, 9(2), 155-169. 
Kostrubiec, V., Tallet, J., \& Zanone, P.-G. (2006). How a new behavioral pattern is stabilized with learning determines its persistence and flexibility in memory. Experimental Brain Research, 170(2), 238-244.

Kostrubiec, V., \& Zanone, P. G. (2002). Memory dynamics: Distance between the new task and existing behavioural patterns affects learning and interference in bimanual coordination in humans. Neuroscience Letters, 331(3), 193-197.

Lafrenière, M.-A. K., Jowett, S., Vallerand, R. J., \& Carbonneau, N. (2011). Passion for coaching and the quality of the coach-athlete relationship: The mediating role of coaching behaviors. Psychology of Sport and Exercise, 12(2), 144-152. doi: 10.1016/j.psychsport.2010.08.002

Locke, E. A., \& Latham, G. P. (2002). Building a practically useful theory of goal setting and task motivation: A 35-year odyssey. American Psychologist, 57(9), 705-717.

MacPherson, A., Collins, D., \& Morriss, C. (2008). Is what you think what you get? Optimizing mental focus for technical performance. Sport Psychologist, 22(3), 288303.

MacPherson, A. C., Collins, D., \& Obhi, S. S. (2009). The importance of temporal structure and rhythm for the optimum performance of motor skills: A new focus for practitioners of sport psychology. Journal of Applied Sport Psychology, 21(1 supp 1), $48-61$.

MacPherson, A. C., Turner, A. P., \& Collins, D. (2007). An investigation of natural cadence between cyclists and noncyclists. Research Quarterly for Exercise and Sport, 78(4), 396-400.

Magyar, T. M., \& Duda, J. L. (2000). Confidence restoration following athletic injury. The Sport Psychologist, 14(4), 372-390.

Markova, I. (1987). Human Awareness. London, UK: Hutchinson Education. 
Martens, R. (1987). Coaches Guide to Sport Psychology. Champaign, IL: Human Kinetics.

Masters, R., \& Maxwell, J. (2008). The theory of reinvestment. International Review of Sport \& Exercise Psychology, 1(2), 160-183.

Masters, R. S. W. (1992). Knowledge, knerves and know-how: The role of explicit versus implicit knowledge in the breakdown. British Journal of Psychology, 83(3), 343-358.

Maxwell, J. P., \& Masters, R. S. W. (2002). External versus internal focus instructions: Is the learner paying attention? International Journal of Applied Sports Sciences, 14(2), 7088.

Mercado, E., III. (2008). Neural and cognitive plasticity: From maps to minds. Psychological Bulletin, 134(1), 109-137.

Mercado, E., III. (2009). Cognitive plasticity and cortical modules. Current Directions in Psychological Science, 18(3), 153-158.

Minichiello, T., Rose, A., \& Brice, P. (2009). Comeback... The team Jennis way. Paper presented at the UK Sport World Class Performance Conference, Warwickshire, November.

MizunoEurope. (2011, 27 May). Luke Donald on top of the world Retrieved 31 May 2011, from

http://golf.mizunoeurope.com/news/index.php?article=2011_05_27_Donald_disease takes_Luke to_world_1

Moore, W. E., \& Stevenson, J. R. (1991). Understanding trust in the performance of complex automatic sport skills. Sport Psychologist, 5(3), 281-289.

Moore, W. E., \& Stevenson, J. R. (1994). Training for trust in sport skills. Sport Psychologist, 8(1), 1-12.

Newell, K. M., Liu, Y.-T., \& Mayer-Kress, G. (2001). Time scales in motor learning and development. Psychological Review, 108(1), 57-82. doi: 10.1037/0033-295X.108.1.57 
Newell, K. M., Liu, Y.-T., \& Mayer-Kress, G. (2005). Learning in the brain-computer interface: insights about degrees of freedom and degeneracy from a landscape model of motor learning. Cognitive Processing, 6(1), 37-47. doi: 10.1007/s10339-004-00476

Peh, S. Y.-C., Chow, J. Y., \& Davids, K. (2011). Focus of attention and its impact on movement behaviour. Journal of Science and Medicine in Sport, 14(1), 70-78. doi: 10.1016/j.jsams.2010.07.002

Pijpers, J. R., Oudejans, R. R. D., Holsheimer, F., \& Bakker, F. C. (2003). Anxietyperformance relationships in climbing: A process-oriented approach. Psychology of Sport and Exercise, 4(3), 283-304.

Prinz, W. (1990). A common coding approach to perception and action. In O. Neumann \& W. Prinz (Eds.), Relationships between Perception and Action (pp. 167-201). Berlin: Springer.

Ross-Stewart, L., \& Short, S. E. (2009). The frequency and perceived effectiveness of images used to build, maintain, and regain confidence. Journal of Applied Sport Psychology, 21(1 supp 1), 34-47.

Ross, H. (2011). Woods couldn't "make it happen". The Tour Report Retrieved 23 May 2011, from http://www.pgatour.com/tourreport/?http://tourreport.pgatour.com/2011/01/29/woodscouldnt-make-it-happen/

Scanlan, T. K., Carpenter, P. J., Schmidt, G. W., Simons, J. P., \& Keeler, B. (1993). An introduction to the sport commitment model. Journal of Sport \& Exercise Psychology, $15(1), 1-15$.

Schoen, D. A. (1983). The Reflective Practitioner. New York: Basic Books. 
Schöllhorn, W. I., Mayer-Kress, G., Newell, K. M., \& Michelbrink, M. (2009). Time scales of adaptive behavior and motor learning in the presence of stochastic perturbations. Human Movement Science, 28(3), 319-333. doi: 10.1016/j.humov.2008.10.005

Schorer, J., Baker, J., Fath, F., \& Jaitner, T. (2007). Identification of Interindividual and Intraindividual Movement Patterns in Handball Players of Varying Expertise Levels. Journal of Motor Behavior, 39(5), 409-421.

Singer, R. N. (1988). Strategies and metastrategies in learning and performing self-paced athletic skills. Sport Psychologist, 2(1), 49-68.

Singer, R. N. (2000). Performance and human factors: considerations about cognition and attention for self-paced and externally-paced events. Ergonomics, 43(10), 1661-1680.

Singer, R. N., DeFrancesco, C., \& Randall, L. E. (1989). Effectiveness of a global learning strategy practiced in different contexts on primary and transfer self-paced motor tasks. Journal of Sport \& Exercise Psychology, 11(3), 290-303.

Singer, R. N., Lidor, R., \& Cauraugh, J. H. (1993). To Be Aware or Not Aware? What to Think About While Learning and Performing a Motor Skill. Sport Psychologist, 7(1), 19-30.

Smith, A., Adler, C. H., Crews, D., Wharen, R. E., Laskowski, E. R., Barnes, K., Bell, C. V., Pelz, D., Brennan, R. D., Smith, J., Sorenson, M. C., \& Kaufman, K. R. (2003). The 'Yips' in Golf: A Continuum Between a Focal Dystonia and Choking. Sports Medicine, 33(1), 13-31.

Smith, D. J. (2003). A framework for understanding the training process leading to elite performance. Sports Medicine, 33(15), 1103-1126.

Steinberg, G. M., \& Glass, B. (2001). Can the Five-Step Strategy enhance the learning of motor skills in older adults? Journal of Aging \& Physical Activity, 9(1), 1-10. 
Stevenson, J. R., Moore, B., Pinter, M., Stephenson, P., Liley, M., Elliot, D., \& Brossman, M. (2007). Effects of trust training on tee and pitch shots in golf. International Journal of Sports Science and Coaching, 2(1), 47-66.

Tallet, J., Kostrubiec, V., \& Zanone, P.-G. (2010). Proactive transfer of learning depends on the evolution of prior learned task in memory. Human Movement Science, 29(3), 349368.

Tallet, J., Kostrubiec, V., \& Zanone, P. G. (2008). The role of stability in the dynamics of learning, memorizing, and forgetting new coordination patterns. Journal of Motor Behavior, 40(2), 103-116.

Theodorakis, Y. (1996). The influence of goals, commitment, self-efficacy and selfsatisfaction on motor performance. Journal of Applied Sport Psychology, 8(2), 171182.

Trow, P. (1993, 6 June ). Golf: The rewards of putting it right: Bernhard Langer has three times cured the putting 'yips'. The Independent Retrieved on 15 October, 2010, from http://www.independent.co.uk/sport/golf-the-rewards-of-putting-it-right-bernhardlanger-has-three-times-cured-the-putting-yips-paul-trow-outlines-his-strongarmtactics-1489885.html.

Tyler, R. W. (1949). Basic Principles of Curriculum and Instruction. Chicago: University of Chicago Press.

Vallée, C. N., \& Bloom, G. A. (2005). Building a successful university program: Key and common elements of expert coaches. Journal of Applied Sport Psychology, 17(3), 179-196.

Vealey, R. S. (2001). Understanding and enhancing self-confidence in athletes. In R. N. Singer, H. A. Hausenblas \& C. M. Janelle (Eds.), Handbook of Sport Psychology (2nd ed., pp. 550-565). New York: John Wiley \& Sons, Inc. 
Watzlawick, P., Weakland, J. H., \& Fisch, R. (1974). Change. New York: Norton.

Weiss, W.M., Weiss, M.R, \& Amorose, A.J. (2010). Sport commitment among competitive female athletes: Test of an expanded model. Journal of Sports Sciences, 28(4), 423434.

Williams, A. M., \& Hodges, N. J. (2005). Practice, instruction and skill acquisition in soccer: Challenging tradition. Journal of Sports Sciences, 23(6), 637-650.

Woodman, T., \& Hardy, L. (2003). The relative impact of cognitive anxiety and selfconfidence upon sport performance: a meta-analysis. Journal of Sports Sciences, 21(6), $443-457$.

Wulf, G. (2007). Attention and Motor Skill Learning. Champaign, IL: Human Kinetics. 
Table 1

The Five-A Model of Technical Change

\begin{tabular}{|c|c|c|c|c|}
\hline Stage & Aims & Exemplar Tools (from the literature) & \begin{tabular}{|c|} 
Theories \\
\end{tabular} & Supportive Research \\
\hline Analysis & $\begin{array}{l}\text { Provide an } \\
\text { individualised } \\
\text { diagnosis and } \\
\text { prescription to the } \\
\text { problem. } \\
\text { Consider the pros vs. } \\
\text { cons (e.g. to make the } \\
\text { change at all? When? } \\
\text { How? Refine or } \\
\text { regain?). } \\
\text { Address the reason } \\
\text { for change, including } \\
\text { the specific technical } \\
\text { aspect. } \\
\text { Gain athlete } \\
\text { commitment }\end{array}$ & $\begin{array}{l}\text { Three-dimensional analyses. } \\
\text { Questioning, 2D analysis, inclusion of athlete, } \\
\text { coach and psychologist. Emphasis on volunteer } \\
\text { element. } \\
\text { Two and three-dimensional analyses in practice } \\
\text { and competition, given by coaches and experts to } \\
\text { determine the cause of the problem. Establish the } \\
\text { reason for change and the interdisciplinary } \\
\text { methods of change. }\end{array}$ & $\begin{array}{l}\text { The technical component selected for change } \\
\text { must reflect the cause of error, if indeed the } \\
\text { cause of error can be determined as being } \\
\text { caused by technique. It is therefore essential for } \\
\text { the highlighted problem to be directly linked } \\
\text { with correctly associated kinematics and } \\
\text { tolerances of functional variability. As such, } \\
\text { prescriptions should be highly individualised } \\
\text { and discerning to the individual. Adopting an } \\
\text { expert-model approach can be flawed on the } \\
\text { premise that highly skilled athletes demonstrate } \\
\text { high inter- and intra-individual variability. } \\
\text { Athlete involvement analysis also enhances } \\
\text { empowerment, cohesion, and motivation } \\
\text { towards programme adherence. Addressing the } \\
\text { requirement for a buying into the process. This } \\
\text { is facilitated by respect, value and trust } \\
\text { exchanged by the coach and athlete. The use of } \\
\text { highly objective and accurate tools to evaluate, } \\
\text { help "sell" the process as most beneficial to the } \\
\text { athlete. Therefore the objectivity of diagnostic } \\
\text { procedures serves an important dual function at } \\
\text { this stage. }\end{array}$ & $\begin{array}{l}\text { Armstrong (2001); } \\
\text { Bass, (1999); Butler \& } \\
\text { Hardy (1992); Davids, } \\
\text { Button, Araújo, } \\
\text { Renshaw \& Hristovski } \\
\text { (2006); Desjardins } \\
\text { (1996); Jones (1993); } \\
\text { Lafreniere et al. (2011); } \\
\text { Magyar \& Duda } \\
\text { (2000); Schorer, Baker, } \\
\text { Fath, \& Jaitner (2007); } \\
\text { Theodorakis (1996); } \\
\text { Vallée \& Bloom } \\
\text { (2005); Windee et al. } \\
\text { (2010). }\end{array}$ \\
\hline Awareness & $\begin{array}{l}\text { Call into } \\
\text { consciousness the } \\
\text { current technique vs. }\end{array}$ & $\begin{array}{l}\text { Contrast/awareness drills (correct vs. incorrect) } \\
\text { within simplified/modified tasks. Generation of } \\
\text { cues for each position. Self-rating scale to }\end{array}$ & $\begin{array}{l}\text { Reframing, distinction, "noise" and large } \\
\text { sudden changes in movement creates a } \\
\text { necessary realisation of change. The generation }\end{array}$ & $\begin{array}{l}\text { Bar-Eli (1991); } \\
\text { Kostrubiec \& Zanone } \\
\text { (2002); Kostrubiec et }\end{array}$ \\
\hline
\end{tabular}


the desired new

technique.

Adjustment

Modify and correct

the flaw in technique. differentiate the two. Incorrect positioning drills gradually faded out.

Mental and physical contrast of the current followed by new technique with instruction. Self reports.

Positioning manipulation in isolated task, awareness of kinaesthesia and generation of cues. Continuous discussion with experts as to the cause/solution to the problem, aided by video, goal setting and self-reported confidence levels. Introduction to contrast task with lower stress (weight), development of cues and mental imagery script.

Gradual return to normal task conditions, regular use of contrast drills. Coach and video feedback. Introduction of a holistic-rhythm based cue.

Contrast trials, calling "old/new way". Confirmatory video analysis.

Progressive imagery based on visual and kinaesthetic aspects of best attempts with integrated cues which were discussed in each debrief session. Self-model was viewed from video. Video of other well established skills enhanced confidence. of new alternatives serves to distinguish between two movement outcomes and drive the change process, preventing return to the previous or a newly formed movement pattern in between the current and desired change.

Practice must progress towards the new movement pattern, meaning this stage is characterised by a varied emphasis within training. To achieve this change, key aspects of the environment, task and athlete performance states must be gradually introduced whilst increased demand is put on executing the new technique. As such, less demand is put on contrast in comparison to the awareness stage. Reinforcement plays an important role during this transition, helping to introduce clarity and confidence to the athlete as well as maintaining motivation through goal setting/monitoring. This stage can be conceptually compared to differential learning, whereby the learner is encouraged to search for and progress towards more functional movement patterns. This is aided by the coach's introduction and eventual removal of various constraints, indicating the possibility for a non-directed, but practice directed search for a new movement solution. al. (2006); MacPherson et al. (2007); Mercado (2008, 2009);

Schöllhorn, et al.

(2009); Tallet et al.

(2008); Tallet et al.

(2010).
Carson et al. (submitted); Collins et al. (1999); Frank Michelbrink,

Beckmann \&

Schöllhorn (2008);

Hanin et al. (2004);

Kostrubiec et al.

(2006); MacPherson et al. (2007); Schöllhorn, et al. (2009). 
(Re) Automation Internalise the change to the extent that it is no longer within conscious awareness.

\section{integrated with strenuous physical training.}

Continued drills with holistic rhythm-based cue Monitoring from self and coach.

Variable practice of the new technique, under fatigue from previous stages.

Increase of repetitions and weight load. Imagery script refined, confidence built with self-set goals attained.

Competitive, pressured simulations, with 3D analyses (including after 2 years)

whereby the athlete

and coach do not

require further need

for additional

modification.
Confidence and enthusiasm on the day of alteration. Follow-up timed trials after 2 days, 3 days, 2 and 4 weeks and 8 months (mixture of practices and competitions).

Competitive simulations. Video and 3D feedback. Imagery script refined and introduced into the pre-event strategy. Follow-up 3D data collected after 3,16 and 55 weeks of the intervention.
Automaticity facilitates higher order processing of task and environmental stimuli into the planning and execution of skilled movements.

This is because attention does not have to be

directed towards the actual execution. A self-

focus on a movement constituent can serve to

disrupt the flow and timing of execution,

representing regressions in both psychological

processing and technical ability. This is seen in cases of high pressure where negative

cognitions, emotions and anxiety interpretations are likely to be at their highest. Re-automating the movement change is thus essential to return the performer to the necessary levels of

consistency as exhibited prior to change itself.

Proof of robustness is an important determinant at this stage. Future intervention should follow a proactive rather than remedial strategy, optimising the psychosocial integration, especially confidence, within the process to maintain assurance that the change has been secured. A key consideration at this stage in maintaining and building confidence, is to

consider what proof is given (detail of measures) and from whom it is given by (considered/trusted expert).
Bargh \& Cartrand (1999); Beilock \& Carr (2001); Hill, Hanton,

Matthews \& Fleming

(2010); MacPherson et

al. (2008); Masters

(1992); Masters \&

Maxwell (2008).

Carson et al

(submitted); Collins et al. (1999); Hanin et al. (2004); Hays, Thomas, Maynard \& Bawden

(2009); Moore \&

Stevenson (1991,

1994); Ross-Stewart \&

Short (2009); Vealey

(2001). 
